\title{
Approaches to Working with Children and Families: A Review of the Evidence for Practice
}

\section{Catherine Goodall, Dr Adam Barnard}

Social Work and Professional Practice,, Nottingham Trent University, Nottingham, UK

Catherine Goodall is the lead associate on a 30month KTP project with Nottingham Trent University and Nottinghamshire County Council to review, evaluate and innovate children's services. Catherine has an MA in International Relations and a BA (Hons) in Social and Cultural Studies and a varied employment history in Administration, Project Management and Research. This project has a specific interest in the approach taken to working with children and families, and in parenting support, and will employ Participatory Action Research (PAR) with children and families.

Dr Adam Barnard has been employed in higher education since 1996. His career to date spans the range of social sciences and he has worked with a variety of student groups in Higher Education. He is co-programme leader on the professional doctorate programme at Nottingham Trent. He was programme leader for BA (Hons) Health and Social Care. He teaches on level one, two and three of this programme and teaches Values and Interpersonal Skills on BA (Hons) Social Work. He is engaged in doctoral supervision. He is a member of the school's ethics committee. 


\section{Approaches to Working with Children and Families: A Review of the Evidence for Practice}

This paper explores a range of approaches to working with children and families within Children's Services and Children's Social Care, in a UK local authority context. There are a variety of established approaches, supported by different concepts and theories. Given the substantial recent and developing changes in the political, social and economic context for supporting families in need, collating academic and practical evidence to inform both theory and decision making is vital. The article has a practice focus for Children's Services, but it is also relevant and has implications for a much wider readership. Evidence was gathered through a purposive and rapid review, and aggregated with practice evidence from various sources. An array of issues is considered relating to the context, theory, application, implementation and evaluation of taking one or several approaches. Overall, there is a very limited evidentiary basis, either from research or local authority practice, for adopting any one, wholesale approach to working with children and families in a local authority context over another, but there is emerging evidence of the benefits that certain models and approaches could have, and anecdotally the decision to adopt one formal model appears to be increasing.

Keywords: approach; children; families; social work; local authority; policy;

\section{Introduction}

This paper will provide a review of a range of approaches to working with children and families, collating evidence from literature and practice. Formal models, general approaches, theories and concepts are considered, all of which have implications for both academia and practice.

It is clear from existing research that whilst some evidence is emerging to support the use of a number of approaches in specific contexts, there has been little evaluation of the impact of adopting an approach, and virtually no sustained comparisons between different approaches in terms or impact or outcomes. 
This paper was generated through a Knowledge Transfer Partnership project between a UK University and a County Council to review and improve service design and delivery. A rapid review was conducted of the literature from journals, databases and library catalogues, and this was combined with information from widely available information on practices across the UK. Practical evidence was purposefully selected to mirror that which is accessible to services, managers and practitioners.

\section{Context}

The lives of children and families are diverse, changing and complex, and children's services provision and practice are equally so. Real and perceived distinctions between children's social care staff and other practitioners, between theory and practice, and structural and organisational intricacies, complicate matters further. This is compounded by the range of organisations involved in providing services, the tensions between central and local government, and the major reductions on resources forecast. With these substantial political, social and economic changes, it is vital to critically evaluate how to work with children and families, to ensure that services are appropriate and cost effective.

Children's services are driven by the principles of making children and families' lives safer and happier, yet whilst 'safety, permanency and well-being are worthy practice goals...they are not sufficient as a theoretical framework for child welfare policy and practice'(Lawler et al. 2011, 473-480:473). Indeed, it has been argued that 'too often, the assumption in our field is that good intentions lead to better outcomes'(Axford and Morpeth 2013, 268-277). Whilst a commitment to protecting children and families and ensuring that they prosper is important, alone it may not be sufficient to guarantee success. It is therefore essential to examine and discuss the possible alternatives, bridging the commonly experienced gap between theory and practice (Herie and Martin 2002, 85-95).

Political motivations and principles can have wide ranging and long term effects, which can influence the degree of control available over adopting any one approach. For instance, 
funding from central government is decreasing, the structure of this funding is changing as payment is being linked to results, and schools are being given increasing control via pupil premium, which moves resources and responsibilities from Children's Services to schools.

\section{Theories and Models}

\section{Limitations of evidence reviewed}

A high proportion of the evidence considered in this paper is based on limited research which draws conclusions based on qualitative evidence, rather than firm evidence of outcomes or impact for children and families (Barlow et al. 2012:9). Similarly, much of the research evidence draws conclusions for the positive effects of certain systems, structures and approaches, however due to the intensely complex and contested nature of children's services, none of this appears to have been attributed only to a change in approach. This list of theories and approaches is by no means exhaustive, but represents the most accessible and commonly employed approaches, some of which are complementary or overlap with others.

The following are examples of core principles, theories and models for approaches to working with children and families. Evidence appeared more readily available for the use of theories in a social work context than in the more general children's services setting.

\section{Psychosocial theories}

Psychosocial theories, influenced by psychology and Freudian psychoanalysis, can be traced in social work practice to the 1920s (Healy 2005). Focusing on locating problems, and the capacity to overcome these, within the individuals and the family itself (Sheldon and Macdonald 2009), 'goals to restore, maintain, and enhance the personal and social functioning of individuals' are central (Goldstein 2008). These theories 'emphasize the importance of people's feelings...in creating and resolving the problems that they face', and have historically been more prominent in the US and other countries, than in UK based social work practice (Payne 2014:95).

Overall, the evidence for the use of psychosocial theories is strong, the principles of psychosocial theories are influential and embedded within social work practice, and could have 
potential benefits as part of a formal approach (Payne 2014). However, psychosocial theories are unlikely to be sufficient on their own to form a single approach for the whole workforce in working with children and families due to a lack of associated practice guidance and tools.

\section{Psychodynamic theories}

Psychodynamic practices place the practitioner in a position of power, with expertise and control, operating on the understanding that service users can be enabled to overcome their problems (Mishna et al. 2013, 289-303). Some psychodynamic theories are used for complex clinical practices which require high levels of clinical expertise and resources, making them effective yet difficult to apply widely in practice with children and families (Healy 2005). These theories differ from person centred practice where service users are involved in a different balance of power (Murphy et al. 2013, 703-719:705).

A range of evidence suggests that psychodynamic practices are varyingly effective in different contexts. Conflicting evidence on the efficacy of psychodynamic approaches is in part due to its wide variety of contexts, settings and applications within children's services (Mishna et al. 2013, 289-303). Recently some 'evidence that psychodynamic treatment has a longer, sustaining effect than other models (e.g. systemic family therapy and cognitive behaviour therapy)' with children has emerged (Mishna et al. 2013, 289-303:297). However, this evidence relates to individual treatments which employ psychodynamic theories, rather than as general approaches. Whilst evidence supports psychodynamic practice in a range of interventions, there has been little practical or theoretical exploration of how psychodynamic theory may inform a general approach to working with children and families. This represents an area of opportunity for further development in practice and research.

\section{Attachment theory}

Originating with the work of Bowlby (1969), attachment theory proposes that a child's early attachment to its mother or primary care givers is crucial for various stages of development (Mennen and O'Keefe 2005, 577-593:578; Bowlby 1969). It holds that attachment is 'a persistent affective tie that binds one person to another' (Johnson and Fein 1991, 391-412:406). 
Attachment is understood as a genetic, cognitive and behavioural imperative, and this assertion has been supported in recent neuro-scientific research (Haight et al. 2008, 195-207:197). Consequently 'the nature of the attachment between parent and child should be a major factor in the decision of what kinds of services to provide the family' (Mennen and O'Keefe 2005, 577593:578).

Whilst attachment theory is in popular use across a number of disciplines, it has received criticism for potentially leading to negative outcomes if misunderstood in practice with children (Johnson and Fein 1991, 391-412:397). There are also competing understandings of the application of attachment theory to specific practice, such as in foster care (Lewis 2001, 67-83). A lack of evaluation and testing of its application to practice has been noted (Tucker and MacKenzie 2012, 2208-2219). An overreliance on attachment theory alone, could therefore lead to an increase in risks for children and families, if preserving attachment takes priority over safeguarding concerns (Bacon and Richardson 2001, 377-397:282).

Overall, attachment theory can be extremely beneficial in understanding children and families and evidence suggests that it should factor into assessments and decision making, however focusing solely on attachment could increase risks and problems in working with families. Attachment theory alone would not be sufficient for an approach to working with children and families, but an understanding of attachment can inform any approach adopted.

\section{Cognitive behavioural approaches}

Originating in psychology and psychiatry, cognitive behavioural (CB) approaches are in popular use across a range of services and systems (Myers 2005, 97-112:100). These approaches focus on current behaviours of individuals and how these may be changed or adapted to improve their situation, without focusing on wider causes of problems and past experiences.

$\mathrm{CB}$ approaches are regarded as rigorous and effective, if employed with adherence to training and guidelines (Sheldon and Macdonald 2009:154). There is a difficulty in establishing an evidence base for a broad cognitive behavioural approach for children's services as much of the available evidence relates to Cognitive Behaviour Therapy (CBT) specifically. CBT as an 
individual treatment has substantial evidence of effectiveness in a range of specific and clinical settings, but it is more difficult to establish evidentiary support for a general CB approach (Scott and Stradling 1991, 533-544:544).

$\mathrm{CB}$ approaches have faced critique in social work for obscuring or overlooking the importance of cultural and structural effects on families (Healy 2005). The focus on individuals and their capacity to improve their own lives is generally viewed positively, but can have a negative impact if the wider influences and causes of problems for children and families are overlooked or misunderstood, particularly when socioeconomic deprivation and social exclusion are key issues for families (Axford and Morpeth 2013, 268-277).

Overall, cognitive behavioural approaches and interventions are proven to be effective in a number of settings. The principles of CB approaches, and specific clinical interventions based upon them, could form part of an approach, but due to the degree of clinical expertise required to employ this in practice, it is unlikely to be practical as a single approach in practice.

\section{Systemic theories}

'Systemic' is a general term covering varied approaches and principles. Systemic family practices hold that the family is a system, related to wider systems in the community and society (Forrester et al. 2013). These types of approaches have grown in significance and popularity in recent years, particularly in the light of their support in the Munro reviews (Munro 2011).

Systemic theory can inform practice, providing insight into the effects and influences of systems on and with children and families. Interventions including Multisystemic Therapy (MST) and family systems therapy, employ systemic theory and have been shown to have positive effects (Sheldon and Macdonald 2009). MST in particular has a strong evidence base, yet is also costly, used in limited specific settings and requires a range of resources to be effective (Littell 2008, 1299-1317:1302).

The use of systems theory within children's services, which considers the structural and organisational factors of systems has been the focus of increasing research. Munro (2010) argued that adopting a 'systems approach will help to understand how and why previous 
reforms have had both beneficial and adverse consequences and...how the system supports social workers and other professionals'(Munro 2010:10).

'A major advantage of the systems model is its broad scope' (Hepworth and others 2010:14), yet this can be extremely complex, providing limited practice guidance and making it difficult for workforces to employ effectively (Payne 2014:184). For instance difficulties implementing a systems approach are demonstrated where families receive very different services based on differing entry points or practitioners' perspectives (Morris 2012, 906920:10).

Overall, systemic and systems theories are supported by research evidence and policy drivers, and are increasingly employed. General systemic theory can be beneficial in working with children and families, and specific interventions such as MST can be effective in certain settings. Employing systemic theory and practice across the workforce is possible, but considering the existing difficulties with implementation, the specifics of practical application may need to be established and tested locally.

\section{Social democratic theory}

In general, democratic theories focus on children and families' rights, strengths and potential to change. A range of different approaches are social democratic, including feminist, critical, empowerment, advocacy and strengths-based approaches. Within these models all assessments and interventions 'should place the service user at the centre of the process, valuing their perspective as a contributing partner' (Baldwin and Walker 2009, 209-243:227). In these approaches, 'the social worker-service user relationship is viewed as a central and key component of bringing about change'(Murphy et al. 2013, 703-719).

These approaches focus on helping service users to develop greater control over their lives, and to be involved in their service provision (Payne 2014:294). However, the balance between a focus on children and families as individuals with the capacity to change, against the statutory need to protect them from risks, is difficult to achieve particularly considering that often 'protecting children (shielding them from painful discussions and difficult decisions) tends 
to increase their powerlessness' (Toros et al. 2013, 1015-1022:1020). Whilst on the surface it may appear that work with children and families is person-centred in nature, it has been suggested that a person-centred approach alone is incompatible with statutory services due to the difficulties in balancing rights and risks (Murphy et al. 2013, 703-719).

Overall, there is significant discussion of the positive impact that a social democratic focus on strengths and rights can have for service users, and these theories could inform an approach. However, given the apparent tensions between a social democratic focus and the demands of statutory services, a singularly social democratic approach may be inappropriate, or prove difficult to implement.

\section{Social pedagogy}

Originally developed in education, social pedagogy is not a method, but a perspective 'based on the belief that you can decisively influence social circumstances through education' (Hamalainen 2003, 69-80:71). 'Pedagogy' relates to education and the practice of teaching and learning, and the 'basic idea of social pedagogy is to promote people's social functioning, inclusion, participation, social identity and social competence as members of society' (Hamalainen 2003, 69-80:76).

Key principles are: that children, families and practitioners are whole and complete individuals with the capacity to influence their situation; relationships are important and listening and communication are vital; collaboration and team work is emphasised; the rights of service users are paramount; and reflection on practice and changes for families is central (Holthoff and others 2011:9). Whilst popular across mainland Europe, this has not acquired much standing in the UK to date meaning that there is a lack of sustained evidence to support the use of this as an approach in this context (Berridge et al. 2011:6).

Overall, social pedagogy appears to have beneficial elements which could have a positive influence, however there is currently a lack of sustained evidence of the impact as an approach to working with children and families. Social pedagogy can guide working with children and families, but does not in itself provide methods or interventions for doing so. 


\section{Whole family approaches}

Whole family approaches operate on the understanding that work cannot be successfully carried out with any child or a family member in isolation from the others (Adams, Dominelli, and Payne 2009:308). These approaches have been viewed positively both in research and in government guidance and policy (Morris et al. 2008).

However, 'the knowledge base for practice is thin and, often, the actual level of family engagement in practice is limited' (Morris 2012, 906-920:10). Indeed, 'it cannot be assumed that whole family approaches are appropriate or useful for all families or for all needs' (Morris et al. 2008:2). In reality, despite widespread acceptance of the positive influence whole family approaches can have, evidence of their use in practice is limited (Morris et al. 2008).

This is due in part to the need to conduct a whole family assessment of the needs of the whole family as well as the relationships between them (Kendall et al. 2010:10). Such an assessment would be a substantial alteration for many children's services departments and agencies, often divided into children's and adult's sectors. Due to these issues, few local authorities have adopted a whole family assessment process, making it difficult to gain evidence on any impact from this (Akister 2006, 531-546).

Practice Example: The ‘Think Family’ pilot used a whole family approach by 'making sure that the support provided by children's, adults' and family services is co-ordinated and focused on problems affecting the whole family' (Department for Children, Schools and Families, DCSF. 2010). These approaches were piloted in programmes in 15 Family Pathfinder local authorities between 2007 and 2009. These aimed to 'develop and test the effectiveness of intensive, family focused approaches to addressing the needs of families who face multiple and complex problems'(York Consulting 2011:i).

This pilot focused specifically on families with severe and complex needs and was not tested in comparison to alternatives. The evaluation found that this approach had significant positive effects on around $45 \%$ of families, with only around $13 \%$ experiencing worsening problems or increased needs, which was attributable mostly to changes in their circumstances. Work with families was estimated to cost $£ 34,560$ and bring an average net benefit of $£ 15,327$ 
per family. In particular, the evaluation found that using a specific dedicated worker, implementing effective leadership and creating sustainable, long term family care plans were particularly effective (York Consulting 2011).

Overall, whilst a whole family approach is supported by policy developments it appears challenging to implement. To employ a true whole family approach would require a substantial change to working practices in many services and organisations, requiring creative solutions to service design and delivery, yet the potential benefits for families in doing so could be considerable. The principles of understanding and supporting the whole family appear important and could inform any approach to be adopted.

\section{Signs of Safety}

Signs of Safety, developed by Turnell and Edwards in Australia in the 1990s, is a model which appears anecdotally to be increasingly adopted in local authorities across the country. 'It aims to work collaboratively and in partnership with families and children to conduct risk assessments and produce action plans for increasing safety and reducing risk and danger by focusing on strengths, resources and networks that the family have'(Bunn 2013).

The model is simple and asks 3 fundamental questions to each assessment, which are: What are we worried about? What is working well? What needs to happen? (Turnell and Edwards 1997, 179-190). The current status and potential for improvement of cases is rated from 0 to 10, where 0 indicates certainty that the child will be (re)abused and 10 represent safety to the point where the case can be closed.

The inclusion of children in the process is viewed as valuable considering their frequent absence from proceedings, and the benefits that their inclusion can have (Bunn 2013:69). There has been critique of the model in its applicability for use in child protection cases and its potential for overlooking risks (Myers 2005, 97-112). Also, in a review of models and approaches, Signs of Safety was shown to be limited in the number of domains it assesses with families, and also lacking in depth and clarity of guidance for practice (Barlow et al. 2012). Bunn's (2013) review identified positive aspects of the model including engaging children and 
families, its adaptability and the provision of tools and assessments. However this also identified that there is little independent research which demonstrates the effectiveness of the approach in terms of outcomes (Bunn 2013).

Overall, Signs of Safety has positive elements which have been shown to be effective with families in some studies, such as the principles of high levels of service user engagement, focusing on strengths and capacity to change, and the creation of sustainable and long term care plans for families. There appear to be practical issues with implementation and concerns over the adequacy of the model to deal with issues of risk. There are a lack of comparative reviews between this and other models, and of sustained evaluation of the impact of adopting the model over time, and its outcomes for children and families.

\section{Solely Social Care Approaches}

An apparent recent trend is the adoption of widespread changes within Children's Social Care alone, rather than the wider workforce. These changes have been shown to have limited positive effects within narrowly defined test contexts.

\section{Systemic units model}

Following the Munro reviews (2011) which called for a more systemic approach to working with families, an increasing number of local authorities are adopting a systemic unit approach based on systems theory (Forrester et al. 2013:4). This involves creating unit in children's social care to deal with cases collaboratively, employing different roles within the team. Cases are discussed, managed, and work with service users is completed as a unit, unlike the traditional structure of a case being allocated to a social worker which is supervised in a linear fashion by senior social workers and managers.

This approach was recently evaluated in one London and two comparator local authorities (Forrester et al. 2013). Using a range of qualitative methods and observation to explore the influence of the approach on departments, the report details positive findings. However these positive findings were not attributable only to the systemic approach, and there was 'little data that could be considered to relate to 'outcomes' for children or parents' within 
the evaluation (Forrester et al. 2013:19). It also considers how this form of unit is extremely resource intensive and costly. The evaluation indicates positive but ultimately inconclusive findings on this radically different formation for social work provisions.

Overall, the evidence is yet to be gathered which demonstrates the effectiveness of the systemic unit approach over any other, and more sustained evidence of its impact would be valuable. In particular considering its very different structure compared to current provisions which would involve significant investment in time, resources, staff and reconfiguration of services to employ.

\section{Safeguarding Assessment and Analysis Framework}

As a targeted assessment framework for Children's Social Care, the SAAF provides a systematic, robust, and time-efficient model and a range of methods for assessing and analysing in the safeguarding context. The SAAF involves assessment and analysis of the nature and level of harm to a child or young person, the risk of re/abuse or harm, and the likelihood of successful child protection intervention, using a seven-stage model of assessment, analysis and intervention (Bentovim and others 2009).

Standardised approaches to assessments have faced critique, as they may overlook or ignore much of a family's history, and can have a negative effect on relationship building with service users (Sheldon and Macdonald 2009:95). Research suggests that whilst some practitioners and managers may find rigid procedures and processes accessible or comforting, that over time they can become meaningless 'pro-forma processes'(Stanley et al. 2012, 239250:243).

Evidence supporting the use of a systematic approach such as this in assessments and interventions is growing (Sheldon and Macdonald 2009:170). However, currently there is no 'extensive evaluation data available' for the SAAF, although it is receiving support from the Department for Education and under piloting in authorities across the country (Barlow et al. 2012:9). The results of early stage piloting will be extremely useful in assessing the impact of the SAAF. 


\section{Limitations}

It is likely that there is a wealth of locally held evidence supporting practice which could not be covered in this review, but its general inaccessibility reflects the challenges faced by Children's Services in gaining a comprehensive overview. Further research could be conducted which explores locally held information, to provide a more in depth exploration of the evidence.

\section{Analysis}

It appears that local authorities are increasingly opting to adopt one consistent, formal approach across workforces, although this is more prevalent in Children's Social Care than across the whole workforce. Research suggests that implementing an approach across a whole workforce would be a long-term process requiring agreement, involvement and widespread training over time, yet there appear to be numerous advantages to working in a formalised manner (Payne 2014:41)

Implementation of an approach would be strengthened by clear, regular and rigorous testing and evaluation which includes measuring the impact on systems and processes; performance management information for practitioners, and; outcomes for children and families. Systemic theories support the need to consider the organisational system as a whole, and how changes will influence other areas in working with children and families.

\section{Theory}

No singular, universal definition of what constitutes a family exists, and existing definitions cannot 'always capture the diversity of family forms, traditions and histories', particularly when the structures of families in the UK are changing (Morris et al. 2008:3); (Adams, Dominelli, and Payne 2009). Policy and legislation which relies upon theoretical understandings of families, therefore, could be insufficient in their guidance to Children's Services on how best to understand and work with families. Child protection and safeguarding are crucial, and will shape the way these approaches are read, understood and used in practice (Gorin and Jobe 2013, $1330-1346)$. 
There are numerous difficulties for Children's Services organisations and local authorities in managing the links between theory, practice and outcomes (Connolly 2007, 825837:826). Exploring research evidence, experiences of local practice, and the perspectives and experiences of the workforce across related agencies, is vital in establishing a common agreement locally. For any one approach to be implemented and to be effective, its underlying principles must be made clear, and should be relevant and agreeable to all involved, including service users (D'Cruz and Stagnitti 2008, 156-165). Also, both the interventions used with families and the theories which support these should be evaluated separately on their own merits (Sheldon and Macdonald 2009).

\section{Needs}

Changes to children's services should be focused on and driven by the needs of children and their families within the local area (Sloper 2004, 571-580). A planning, action, critical reflection, development cycle is vital in ensuring that services are appropriate, targeted and relevant to service users (SETF, Social Exclusion Task Force 2008:5). Data collected in this process could be used to demonstrate the impact of services, as well as providing clear, local evidence for commissioning.

Ofsted (2013) acknowledge this, noting that good local authorities 'spent considerable time, energy and focus in understanding front-line practice, in assessing what needed to improve and in ensuring that there was a coherent and urgent plan to address the identified areas of need'(Ofsted 2013:22).

\section{Participation}

Involving children and families in the process of ensuring their protection and welfare may seem essential in theory, yet local authorities and policy makers have generally tended to overlook or ignore service users' experiences and perspectives, particularly when they are deemed at risk (Howarth et al. 2012, 155-162:155). This lack of engagement undermines the design, delivery and reception of services (Beresford 2000, 489-503:495). It is therefore important to emphasise the role that children and families can have in this process. 
Practice example: Swindon Borough Council placed children and their families at the centre in redesigning their children's service provisions (http://archive.c4eo.org.uk/themes/earlyintervention/vlpdetails.aspx?lpeid=382). Before beginning processes of change, the council carried out workshops with around 300 children, young people and families to capture their views and experiences to inform service design and delivery. Substantial involvement of service users on such a scale not only ensures that services are relevant, appropriate and meet service users' needs, but it also places service users at the centre of work to improve their lives and increases their engagement with Children's Services.

\section{A framework}

Adopting an off-the-shelf formal model is not the only method available to Children's Services. A local central framework could be developed which would guide the understanding of children and families, how best to work with them, and provide unity and stability across the workforce. Changes which affect the whole workforce are only likely to be successful if they are implemented in a 'bottom-up' method, with collaboration and consultation of practitioners (Connolly 2007, 825-837).

To create such a framework, the general core principle/s, the desired processes for practice, common intervention strategies and a guide to desired outcomes would need to be established. It is also vital to build consideration of practitioners and their relationships with service users into any approach or framework, as the 'relationship between professionals...and clients is fundamental to ethical and effective practice'(D'Cruz and Stagnitti 2008, 156-165:159).

Practice Example: Connolly established the New Zealand practice framework based on 'three perspectives: child centred; family-led and culturally responsive; and strengths and evidence-based' (Connolly 2007, 825-837). A single approach was studied and implemented which described the principles which all staff would adopt, the interventions which were supported by these principles, and the outcomes for children and families which were anticipated. This framework does not appear to have been evaluated, and therefore its effects on the workforce and children and families cannot be assessed, but it is one example of the 
development of a practice framework. This demonstrates that it is possible to develop a local framework, which may be more appropriate to families' needs than employing an existing model.

\section{Implementation}

The implementation of any approach is a crucial issue. In children's social care in particular, 'training is only likely to be effective if practitioners also have regular times for peer or supervised case discussions in which new thinking can be embedded' (Glaser et al. 2012). As mentioned earlier, successful and effective authorities provide structured support for frontline practitioners and managers (Payne 2014:41).

Implementation is often challenging given that 'children and their families have a range of different needs which do not fall neatly into separate agency segments' (Sloper 2004, 571580:572). Unfortunately, frequently agencies are divided, with separations between children's and adult's services, statutory and discretionary services, and voluntary organisations, despite policy drivers and evidence that a coordinated approach is most effective (D'Cruz and Stagnitti 2008, 156-165:831). At this stage, these are 'limitations of current organisational arrangements for provision... and their capacity to develop holistic responses'(Morris et al. 2008:14).

Given the centrality of multi-agency working to the law, government regulations and statutory procedures, a lack of shared knowledge on how best to achieve this remains a problem for services (Sloper 2004, 571-580:526). Barriers which contribute to this problem include strategic, structural and organisational issues; 'issues concerning professional status and identity'; co-operation and communication between professionals, agencies and families; the working relationships between managers and practitioners, and many others (Sloper 2004, 571580; Moran et al. 2007, 143-151:143); (Katz and Hetherington 2006, 429-439).

To involve, train and support an entire workforce in a single approach would be an extensive undertaking requiring considerable investment over time. 'Social work services are riddled with experiments and practices that have been discontinued once short-term funding ceases as well as mountains of guidance and bureaucracy', demonstrating that changes require 
long term planning, with reflection, evaluation and development built into the process, and contingencies in place for changes and developments in organisations (Perrott 2009, 103208:113).

\section{Conclusions}

This paper has highlighted a range of different approaches for children's services, many of which have great potential for improvement, yet no one model stands out as the most appropriate, effective or efficient. The incredible complexity and difficulty involved in making widespread changes to services and organisations is clear. Research supports the need to openly and critically review the structure, strategy and delivery of children's services, and to debate the possibility, efficiency, effectiveness and costs of potential changes, informed by practitioners and with service users' needs and perspectives at the centre.

A variety of options currently exist for models and approaches to use when working with children and families. Forrester et al, found that their study of local authority implementation of the systemic units model had far wider implications. 'The systemic unit model allows us to re-imagine the delivery of services in fundamentally different ways' (Forrester et al. 2013:23). This opportunity could provide space to re-think current organisational structures and service provision, to ensure that relevant, successful and cost effective support is provided to children and families. It would also provide an ideal environment to conduct research into the implementation and impact of such significant changes.

The lack of clear evidence to support the adoption of any one model or approach is nto necessarily problematic, and instead could provide opportunities for Children's Services departments to review their local landscape, and to establish existing or even home-grown approaches which most closely match their families' needs.

The most efficacious approaches to working with children and families are those which prioritise children's experiences with a recognition of the importance of family relationships, within the wider socioeconomic context. 
This absence of clarity also provides fertile ground for further research, and the chance to gather valuable data and evidence of impact. When so little evidence of outcomes currently exists, rigorous and sustained evaluations of implementation in Children's Services departments would be welcome.

\section{References}

Adams, R., L. Dominelli, and M. Payne. 2009. Social Work: Themes, Issues and Critical Debates. 3rd ed. Hampshire: Palgrave MacMillan.

Akister, J. 2006. 'A Systems Approach: Back to the Future-Response to Munro, E. (2005) 'A Systems Approach to Investigating Child Abuse Deaths'35(4), Pp. 53146.’ British Journal of Social Work 35 (4): 531-546.

Axford, N. and L. Morpeth. 2013. 'Evidence-Based Programs in Children's Services: A Critical Appraisal.' Children and Youth Services Review 35: 268-277.

Bacon, H. and S. Richardson. 2001. 'Attachment Theory and Child Abuse: An Overview of the Literature for Practitioners.' Child Abuse Review 10: 377-397.

Baldwin, N. and L. Walker. 2009. 'Assessment.' In Social Work: Themes, Issues and Critical Debates, edited by R. Adams, L. Dominelli and M. Payne. 3rd ed., 209243. Hampshire: Palgrave MacMillan.

Barlow, J., J. Fisher, and D. Jones. 2012. Systematic Review of Models of Analysing Significant Harm. London: Department for Education.

Bentovim, A., A. Cox, L. Bingley Miller, and S. Pizzey. 2009. Safeguarding Children Living with Trauma and Family Violence : Evidence-Based Assessment, Analysis and Planning Interventions. London: Jessica Kingsley Publishers Ltd. 
Beresford, P. 2000. 'Service User's Knowledge and Social Work Theory: Conflict Or Collaboration.’ British Journal of Social Work 30 (4): 489-503.

Berridge, D., N. Biehal, E. Lutman, L. Henry, and M. Palomares. 2011. Raising the Bar? Evaluation of the Social Pedagogy Pilot Programme in Residential Children's Homes. London: Department for Education.

Bowlby, J. 1969. Attachment and Loss. Vol. 1, Attachment. Harmonsworth: Penguin.

Bunn, A. 2013. Signs of Safety in England an NSPCC Commissioned Report on the Signs of Safety Model in Child Protection. London: NSPCC.

Connolly, M. 2007. 'Practice Frameworks: Conceptual Maps to Guide Interventions in Child Welfare.' British Journal of Social Work 37: 825-837.

D'Cruz, H. and K. Stagnitti. 2008. 'Reconstructing Child Welfare through Participatory and Child-Centred Professional Practice: A Conceptual Approach.' Child and Family Social Work 13 (2): 156-165.

Department for Children, Schools and Families, DCSF. 2010. Parenting and Family Support: Guidance for Local Authorities in England. London: Department for Children, Schools and Families.

Forrester, D., D. Westlake, M. McCann, A. Thurnham, G. Shefer, G. Glynn, and M. Killian. 2013. Reclaiming Social Work? an Evaluation of Systemic Units as an Approach to Delivering Children's Services. London: Tia Goldberg Centre for Social Work and Social Care.

Glaser, D., V. Prior, K. Auty, and S. Tilki. 2012. Does Training in a Systematic Approach to Emotional Abuse Improve the Quality of Children's Services? London: Department for Education.

Goldstein, E. 'Psychosocial Framework.' Oxford University Press, accessed 05/23, 2014 , http://socialwork.oxfordre.com/view/10.1093/acrefore/9780199975839.001.0001/a crefore-9780199975839-e-320?result=1\#acrefore-9780199975839-div1-2465.

Gorin, S. and A. Jobe. 2013. 'Young People Who have been Maltreated: Different Needs- Different Responses?' British Journal of Social Work 43: 1330-1346.

Haight, W., J. Kagal, and J. Black. 2008. 'Understanding and Supporting Parent-Child Relationships during Foster Care Visits: Attachment Theory and Research.' Social Work 48 (2): 195-207.

Hamalainen, J. 2003. 'The Concept of Social Pedagogy in the Field of Social Work.' Journal of Social Work 3 (1): 69-80.

Healy, K. 2005. Social Work Theories in Context. Hampshire: Palgrave MacMillan. 
Hepworth, D., R. Rooney, G. Dewberry Rooney, K. Strom-Gottfried, and J. Larsen. 2010. Direct Social Work Practice: Theory and Skills. CA, USA: Cengage Learning.

Herie, M. and G. Martin. 2002. 'Knowledge Diffusion in Social Work: A New Approach to Bridging the Gap.' Social Work 47 (1): 85-95.

Holthoff, S., A. K. Frorup, M. Fielding, I. Bryderup, and M. Vandenbroeck. 2011. Social Pedagogy and Working with Children and Young People: Where Care and Education Meet. London: Jessica Kingsley Publishers.

Howarth, J., E. Kalyva, and S. Spyru. 2012. "I Want My Experiences to make a Difference' Promoting Participation in Policy-Making and Service Development by Young People Who have Experienced Violence.' Children and Youth Services Review 34: 155-162.

Johnson, D. and E. Fein. 1991. 'The Concept of Attachment: Applications to Adoption.' Children and Youth Services Review 13: 391-412.

Katz, I. and R. Hetherington. 2006. 'Co-Operating and Communicating: A European Perspective on Integrating Services for Children.' Child Abuse Review 15: 429439.

Kendall, S., J. Rodger, and H. Palmer. 2010. The use of Whole Family Assessment to Identify the Needs of Families with Multiple Problems. London: Department for Education.

Lawler, M., P. Shaver, and G. Goodman. 2011. 'Towards Relationship-Based Child Welfare Services.' Children and Youth Services Review 33: 473-480.

Lewis, M. 2001. 'Issues in the Study of Personality Development.' Psychological Inquiry 12 (2): 67-83.

Littell, J. 2008. 'Evidence-Based Or Biased? the Quality of Published Reviews of Evidence-Based Practices.' Children and Youth Services Review 30: 1299-1317.

Mennen, F. and M. O'Keefe. 2005. 'Informed Decisions in Child Welfare: The use of Attachment Theory.' Children and Youth Services Review 27: 577-593.

Mishna, F., M. Van Wert, and K. Asakura. 2013. 'The Best Kept Secret in Social Work: Empirical Support for Contemporary Psychodynamic Social Work Practice .' Journal of Social Work Practice 27 (3): 289-303.

Moran, P., C. Jacobs, A. Bunn, and A. Bifulco. 2007. 'Multi-Agency Working: Implications for an Early-Intervention Social Work Team.' Child and Family Social Work 12: 143-151.

Morris, K. 2012. 'Thinking Family? the Complexities for Family Engagement in Care and Protection.’ British Journal of Social Work 42: 906-920. 
Morris, K., N. Hughes, H. Clarke, J. Tew, P. Mason, S. Galvani, A. Lewis, L. Loveless, S. Becker, and G. Burford. 2008. Think Family: A Literature Review of Whole family Approaches . London: UK Cabinet Office.

Munro, E. 2011. The Munro Review of Child Protection Interim Report A Child's Journey 2011.

Munro, E. 2010. The Munro Review of Child Protection. Part One: A Systems Analysis. London: The Stationery Office.

Murphy, D., M. Duggan, and S. Joseph. 2013. 'Relationship-Based Social Work and its Compatibility with the Person-Centred Approach: Principled Versus Instrumental Perspectives.' British Journal of Social Work 43: 703-719.

Myers, S. 2005. 'A Signs of Safety Approach to Assessing Children with Sexually Concerning Or Harmful Behaviour.' Child Abuse Review 14: 97-112.

Ofsted. 2013. Annual Report 2012-13: Social Care. Manchester: Ofsted.

Payne, M. 2014. Modern Social Work Theory. 4th ed. Hampshire: Palgrave MacMillan.

Perrott, S. 2009. 'Social Work and Organisations.' In Social Work: Themes, Issues and Critical Debates, edited by R. Adams, L. Dominelli and M. Payne. 3rd ed., 103208. Hampshire: Palgrave MacMillan.

Scott, M. and S. Stradling. 1991. 'The Cognitive-Behavioural Approach with Depressed Clients.' British Journal of Social Work 21: 533-544.

SETF, Social Exclusion Task Force. 2008. Think Research: Using Research Evidence to Inform Service Development for Vulnerable Groups. London: Cabinet Office.

Sheldon, B. and G. Macdonald. 2009. A Textbook of Social Work. Oxon: Routledge.

Sloper, P. 2004. 'Facilitators and Barriers for Co-Ordinated Multi-Agency Services.' Child: Care, Health and Development 30 (6): 571-580.

Stanley, T., P. McGee, and H. Lincoln. 2012. 'A Practice Framework for Assessments at Tower Hamlets Children's Social Care: Building on the Munro Review.' Practice: Social Work in Action 24 (4): 239-250.

Toros, K., A. Tiko, and K. Saia. 2013. 'Child-Centered Approach in the Context of the Assessment of Children in Need: Reflections of Child Protection Workers in Estonia.' Child and Youth Services Review 35: 1015-1022.

Tucker, D. and M. MacKenzie. 2012. 'Attachment Theory and Change Processes in Foster Care.' Children and Youth Services Review 34: 2208-2219.

Turnell, A. and S. Edwards. 1997. 'Aspiring to Partnership: The Signs of Safety Approach to Child Protection.' Child Abuse Review 6: 179-190. 
York Consulting. 2011. Turning Around the Lives of Families with Multiple problems - an evaluation of the Family and Young Carer Pathfinders Programme. London: University of London.

\section{Notes on Contributors}

Dr Adam Barnard, Chaucer 3214, Social Work and Professional Practice, Nottingham Trent University, NG1 4BU adam.barnard@ntu.ac.uk

Catherine Goodall, Chaucer 3214, Social Work and Professional Practice, Nottingham Trent University, NG1 4BU $\underline{\text { Catherine.goodall@ntu.ac.uk }}$ 